\section{All-Cause Mortality Among US Veterans of the Persian Gulf War: I3-Year Follow-up}

\author{
Shannon K. Barth, MPH', Han K. Kang, DrPH', and Tim Bullman, MS'
}

Public Health Reports 2016, Vol. I3I(6) 822-830 (C) 2016, Association of Schools and Programs of Public Health All rights reserved. Reprints and permission: sagepub.com/journalsPermissions.nav DOI: $10.1177 / 0033354916676278$ phr.sagepub.com

\begin{abstract}
Objective: We determined cause-specific mortality prevalence and risks of Gulf War deployed and nondeployed veterans to determine if deployed veterans were at greater risk than nondeployed veterans for death overall or because of certain diseases or conditions up to 13 years after conflict subsided.

Methods: Follow-up began when the veteran left the Gulf War theater or May I, 199I, and ended on the date of death or December 31, 2004. We studied 621 90 I veterans who served in the 1990-1991 Persian Gulf War and 746247 veterans who served but were not deployed during the Gulf War. We used Cox proportional hazard models to calculate rate ratios adjusted for age at entry to follow-up, length of follow-up, race, sex, branch of service, and military unit. We compared the mortality of (I) Gulf War veterans with non-Gulf War veterans and (2) Gulf War army veterans potentially exposed to nerve agents at Khamisiyah in March 199I with those not exposed. We compared standardized mortality ratios of deployed and nondeployed Gulf War veterans with the US population.

Results: Male Gulf War veterans had a lower risk of mortality than male non-Gulf War veterans (adjusted rate ratio [aRR] = 0.97; 95\% confidence interval [Cl], 0.95-0.99), and female Gulf War veterans had a higher risk of mortality than female nonGulf War veterans (aRR $=$ I.I5; $95 \% \mathrm{Cl}$, I.03-I.28). Khamisiyah-exposed Gulf War army veterans had $>3$ times the risk of mortality from cirrhosis of the liver than nonexposed army Gulf War veterans (aRR = 3.73; 95\% Cl, I.64-8.48). Compared with the US population, female Gulf War veterans had a $60 \%$ higher risk of suicide and male Gulf War veterans had a lower risk of suicide (standardized mortality ratio $=0.84 ; 95 \% \mathrm{Cl}, 0.80-0.88$ ).
\end{abstract}

Conclusion: The vital status and mortality risk of Gulf War and non-Gulf War veterans should continue to be investigated.

\title{
Keywords
}

gulf war, mortality, veterans

Between August 1990 and July 1991, approximately 700000 US troops were deployed to the Persian Gulf. Potentially harmful exposures during the Gulf War included oil well fire smoke, chemical and biological warfare compounds, multiple vaccinations, depleted uranium, pesticides, and physical and psychological stressors. ${ }^{1-3}$ Concern persists about the possible adverse health effects of service during the Persian Gulf War. Studies show greater illness among Gulf War veterans compared with non-Gulf War veterans, including more self-reported medical and psychiatric conditions and poorer self-perceptions of general health. ${ }^{4-7}$ Gulf War veterans have more psychological illnesses, including posttraumatic stress disorder, and are at greater risk for chronic multisymptom illness than nondeployed veterans. ${ }^{6-13}$ Many symptoms reported by Gulf War veterans - such as back pain, joint pain, headaches, and fatigue - have not been attributable to a diagnosable disease. ${ }^{5}$

Historically, Gulf War and non-Gulf War veterans have had lower overall mortality rates than the US population. ${ }^{14}$
However, Gulf War veterans have had a greater risk of death from accidents, including motor vehicle accidents, than nonGulf War veterans. ${ }^{14-17}$ The risk of death from motor vehicle accidents was greatest within 1 year after leaving the Gulf War theater but decreased after 7 years. ${ }^{14}$

Concerns remain about the long-term health effects of potential exposure to harmful chemicals during the Gulf War. The nerve agents sarin and cyclosarin may have been released when US forces detonated a weapons cache at

\footnotetext{
'Epidemiology Program, Post-Deployment Health Services, Office of Patient Care Services, Veterans Health Administration, US Department of Veterans Affairs, Washington, DC, USA
}

\section{Corresponding Author:}

Shannon K. Barth, MPH, Epidemiology Program, Post-Deployment Health Services (IOP4Q), Office of Patient Care Services, US Department of Veterans Affairs, 810 Vermont Ave NW, Washington, DC 20420, USA. Email: shannon.barth@va.gov 
Khamisiyah, Iraq, from March 10 through March 13, 1991. A greater risk of brain cancer mortality among army Gulf War veterans who were exposed at Khamisiyah as compared with those not exposed was reported at 7 and 13 years after the war. ${ }^{18,19}$ Other studies found associations between exposure at Khamisiyah and cognitive dysfunction, central nervous system pathology, immunosuppression, and decreased neurobehavioral functioning. ${ }^{20-27}$ However, clinical examinations of Gulf War veterans did not find a difference in the prevalence of distal symmetric polyneuropathy between those exposed and not exposed at Khamisiyah. ${ }^{28}$ A health survey of Gulf War veterans found no adverse health effects among army veterans exposed at Khamisiyah. ${ }^{29}$ A study conducted to determine if Khamisiyah exposure could explain the increased risk of motor vehicle crash deaths among Gulf War veterans showed no increase in risk of motor vehicle crash deaths between Khamisiyah-exposed and nonexposed veterans. ${ }^{30}$ Another study found no differences in hospitalizations or self-reported medical conditions 9 years after the war. ${ }^{31}$

Researchers, veterans, and clinicians are concerned about potential health effects resulting from soldiers' exposure to Kuwaiti oil well fires during the Gulf War. Several studies reported an association between acute respiratory conditions and self-reported exposure to oil well fire smoke. ${ }^{32,33} \mathrm{~A}$ survey of Australian Gulf War veterans found a greater frequency of self-reported lung conditions, including asthma, among those exposed to oil well fire smoke, although no evidence for ventilatory abnormalities was found after spirometric testing. ${ }^{33}$ One study found an association between asthma and self-reported exposure to oil well fire smoke among US Gulf War veterans with high levels of exposure. ${ }^{34}$ Another study found no pulmonary abnormalities among Gulf War veterans compared with non-Gulf War veterans 10 years after the war. ${ }^{35}$ Other research found no increase in postwar hospitalizations among Gulf War veterans exposed to oil well fire smoke. ${ }^{36}$

This study extends the follow-up period to 13 years (1991-2004) and compares cause-specific mortality risk among Gulf War veterans, non-Gulf War veterans, and the general US population.

\section{Methods}

The study cohort included 621901 Gulf War veterans and 746247 non-Gulf War veterans. To be eligible for the cohort, Gulf War veterans must have served in the Persian Gulf between August 1, 1990, and March 1, 1991-the period of armed conflict. Troops that arrived in the Persian Gulf after March 1, 1991, were excluded from the cohort. We selected veterans in the non-Gulf War group from a stratified random sample of military personnel, including reserve and National Guard members, who were in the military at the time of the Gulf War but were not deployed to the Persian Gulf. The US Department of Defense's Defense Manpower Data Center supplied data on demographic and military characteristics for the study cohort, including race, date of birth, marital status at entry to follow-up, sex, military rank, branch of service, and unit component (ie, active duty, reserve, National Guard). This study was reviewed and approved by the Washington DC VA Medical Center Institutional Review Board.

For Gulf War veterans, the follow-up period began on the date that the veteran left the theater alive; for non-Gulf War veterans, the follow-up period began on May 1, 1991. Follow-up ended on the date of death or on December 31, 2004, whichever was earlier. We determined vital status by using the US Department of Veterans Affairs database, Beneficiary Identification and Records Locator Subsystem, in combination with the Social Security Administration Death Master File. The Beneficiary Identification and Records Locator Subsystem contains records on veterans who are eligible for death benefits and other benefits and identifies deceased veterans who have not yet been reported in the Social Security Administration file. We obtained cause-ofdeath data from either a death certificate located in the veteran's claim folder or from the National Death Index Plus. Since 1997, the National Center for Health Statistics has provided cause-of-death codes by underlying cause using the International Classification of Diseases. A nosologist blinded to deployment status coded any death certificate obtained from claim folders using the International Classification of Diseases, Ninth Revision (ICD-9). ${ }^{37}$

We used the 2000 plume model developed jointly by the Department of Defense and the Central Intelligence Agency to determine exposure at Khamisiyah. ${ }^{38}$ In our study cohort, 98406 army veterans who were considered potentially exposed to nerve agents were categorized as having been exposed for 1 day or $\geq 2$ days.

The Department of Defense provided data on oil well fire smoke exposure, which are based on air and soil samples gathered during the Gulf War when the fires were burning. ${ }^{39}$ For this study, veterans who were exposed to at least $0.26 \mathrm{mg}$ of total suspended particulate per cubic meter of air for at least 1 day were considered exposed. Based on this criterion, 123478 army veterans in this study cohort were considered exposed. Approximately $13 \%$ of army Gulf War veterans were exposed to nerve agents at Khamisiyah and to oil well fire smoke.

We calculated person-years at risk of dying and compared the relative frequency of overall and specific causes of death between Gulf War veterans and non-Gulf War veterans as well as between Khamisiyah-exposed and nonexposed army Gulf War veterans. We used crude death rates to calculate unadjusted rate ratios. We calculated adjusted rate ratios (aRRs) using Cox proportional hazard models, which included the following covariates: age at entry to followup, length of follow-up, race (white/nonwhite), sex, service branch, and type of military unit. We conducted analyses collectively as well as by sex. The cause-specific categories of mortality and their $I C D-9$ codes included disease-related causes (001-799), infectious and parasitic disease (001-139), 
all cancers (140-208), circulatory system (390-459), respiratory system (460-519), digestive system (520-579), all external causes (E800-E999), all accidents (E800-E929), motor vehicle accidents (E810-E825), suicide (E950-E959), and homicide (E960-E969). Analyses of Khamisiyah-exposed and nonexposed army veterans also controlled for oil well fire smoke exposure and included ICD-9 codes for lung cancer (162), chronic obstructive pulmonary disease (490-492, 494, 496), and cirrhosis of the liver (571).

We calculated standardized mortality ratios (SMRs) to compare observed deaths among veterans with expected deaths based on the US population using the National Institute for Occupational Safety and Health Life Table Analysis System. ${ }^{40}$ We assessed significance using $95 \%$ confidence intervals (CIs). We analyzed data using SAS version 9.4. ${ }^{41}$

\section{Results}

Compared with non-Gulf War veterans, Gulf War veterans were more likely to be male ( $93.0 \%$ vs $86.7 \%$ ), to be younger (mean age in 1991: 28 vs 30 years), and to have served in active component units ( $83.3 \%$ vs $70.2 \%$ ). Gulf War veterans and non-Gulf War veterans were similar in race (most were white), marital status (most were married), and branch of service (most were in the army; Table 1).

From the beginning of follow-up through December 31, 2004, 10869 of 621901 (1.7\%) Gulf War veterans died (rate $=12.8$ per 10000 person-years), and 14716 of $746247(2.0 \%)$ non-Gulf War veterans died (rate $=14.6$ per 10000 person-years; Table 2). Data on cause of death were missing for 770 of $10869(7.1 \%)$ deceased Gulf War veterans and for 1090 of $14716(7.4 \%)$ deceased non-Gulf War veterans. Gulf War veterans had a cumulative total of 8466469 person-years at risk, with an average length of follow-up of 13.6 years. Non-Gulf War veterans had a cumulative total of 10018690 person-years at risk, with an average length of follow-up of 13.6 years.

Compared with male non-Gulf War veterans, male Gulf War veterans had a lower risk of all-cause mortality $(\mathrm{aRR}=$ 0.97; 95\% CI, 0.95-0.99), disease-related causes (aRR = $0.93 ; 95 \%$ CI, 0.90-0.97), and death from infectious and parasitic disease $(\mathrm{aRR}=0.56 ; 95 \% \mathrm{CI}, 0.47-0.68)$ but a slightly higher risk of death from all accidents $(\mathrm{aRR}=$ 1.06; 95\% CI, 1.01-1.12; Table 2).

Compared with female non-Gulf War veterans, female Gulf War veterans had a higher risk of all-cause mortality $(\mathrm{aRR}=1.15 ; 95 \% \mathrm{CI}, 1.03-1.28)$, a higher risk of death from diseases of the digestive system ( $\mathrm{aRR}=2.05 ; 95 \% \mathrm{CI}$, 1.09-3.84), and a higher risk of death from external causes $(\mathrm{aRR}=1.32 ; 95 \% \mathrm{CI}, 1.09-1.60) ; 83 \%$ of these externally caused deaths were from motor vehicle accidents $(\mathrm{aRR}=$ 1.44; 95\% CI, 1.06-1.97), suicide ( $\mathrm{aRR}=1.35 ; 95 \% \mathrm{CI}$, 0.94-1.95), or homicide (aRR $=1.52 ; 95 \% \mathrm{CI}, 0.97-2.40$ ). Overall, we found no significant differences between Gulf War veterans and non-Gulf War veterans for deaths from
Table I. Demographic and military characteristics of US Gulf War veterans deployed between August I, 1990, and March I, I991, and nondeployed veterans who served in the military during the same time period but did not deploy to the Persian Gulf ${ }^{\text {a }}$

\begin{tabular}{|c|c|c|}
\hline Characteristic & $\begin{array}{c}\text { Gulf War } \\
\text { Veterans, No. (\%) }\end{array}$ & $\begin{array}{c}\text { Non-Gulf War } \\
\text { Veterans, No. (\%) }\end{array}$ \\
\hline Total & $621901(45.5)$ & $746247(54.5)$ \\
\hline \multicolumn{3}{|l|}{ Race $^{c}$} \\
\hline White & $436575(70.2)$ & $539537(72.3)$ \\
\hline Black & $143659(23.1)$ & $161189(21.6)$ \\
\hline Other & $41667(6.7)$ & $45521(6.1)$ \\
\hline \multicolumn{3}{|l|}{$\operatorname{Sex}^{c}$} \\
\hline Male & $578368(93.0)$ & $646996(86.7)$ \\
\hline Female & $43533(7.0)$ & 99251 (I3.3) \\
\hline \multicolumn{3}{|l|}{ Rank $^{c}$} \\
\hline Enlisted person & $554736(89.2)$ & $632817(84.8)$ \\
\hline Officer & $67165(10.8)$ & 113430 (I5.2) \\
\hline \multicolumn{3}{|l|}{ Service branch ${ }^{d}$} \\
\hline Army & 322 I $45(5 \mid .8)$ & $415660(55.7)$ \\
\hline Navy & $136196(21.9)$ & 132086 (17.7) \\
\hline Air Force & 71519 (11.5) & 84326 (II.3) \\
\hline Marine Corps & 92041 (14.8) & 114 I75 (15.3) \\
\hline \multicolumn{3}{|l|}{ Type of unit ${ }^{d}$} \\
\hline Active & $518044(83.3)$ & $523865(70.2)$ \\
\hline Reserve & $62812(10.1)$ & 144026 (19.3) \\
\hline National Guard & $41045(6.6)$ & $78356(10.5)$ \\
\hline \multicolumn{3}{|l|}{$\begin{array}{l}\text { Marital status } \\
\text { (at entry to } \\
\text { follow-up) }^{\text {d }}\end{array}$} \\
\hline Married & $337070(54.2)$ & $410436(55.0)$ \\
\hline Not married & 28483 I (45.8) & $335811(45.0)$ \\
\hline $\begin{array}{l}\text { Mean } \pm \text { SD age at } \\
\text { entry to } \\
\text { follow-up, } y^{d}\end{array}$ & $28 \pm 7.1$ & $30 \pm 8.3$ \\
\hline
\end{tabular}

Abbreviation: SD, standard deviation.

aData source: Unpublished data from the US Department of Defense's Defense Manpower Data Center.

${ }^{b}$ Percentages may not total to 100 because of rounding.

${ }^{c} p<.001$ for all comparisons, Mantel-Haenszel $\chi^{2}$ test.

${ }^{\mathrm{d}} P<.00$ I for all comparisons, Satterthwaite $t$ test.

cancer or diseases of the circulatory or respiratory systems (Table 2).

Compared with nonexposed army Gulf War veterans, army Gulf War veterans potentially exposed to nerve agents at Khamisiyah for $\geq 2$ days had a higher risk of mortality from cirrhosis of the liver when controlling for oil well fire smoke exposure $(\mathrm{aRR}=3.73 ; 95 \% \mathrm{CI}, 1.64-8.48)$. Mortality caused by chronic obstructive pulmonary disease among exposed and nonexposed army Gulf War veterans was similar. Likewise, mortality outcomes of army Gulf War veterans who were exposed to oil well fire smoke (controlling for Khamisiyah exposure) were not significantly different from those of nonexposed army Gulf War veterans (Table 3).

Compared with the US population, both Gulf War and non-Gulf War veterans had significantly lower-thanexpected all-cause and disease-related mortality rates. Female Gulf War veterans had a significantly higher risk 
Table 2. Mortality rates and adjusted rate ratios of US Gulf War veterans deployed between August I, 1990, and March I, I99I, and nondeployed veterans who served in the military during the same period but did not deploy, by cause of death, 1991-2004

\begin{tabular}{|c|c|c|c|c|c|c|}
\hline \multirow[b]{2}{*}{$\begin{array}{l}\text { Underlying Cause of Death } \\
\text { (ICD-9 Code) })^{37}: \text { Sex }\end{array}$} & \multicolumn{2}{|c|}{$\begin{array}{l}\text { Gulf War Veterans } \\
\qquad(n=621901)\end{array}$} & \multicolumn{2}{|c|}{$\begin{array}{c}\text { Non-Gulf War Veterans } \\
(n=746247)\end{array}$} & \multirow[b]{2}{*}{$\begin{array}{l}\text { Adjusted Rate } \\
\text { Ratiob }^{\text {b }}(95 \% \mathrm{Cl})\end{array}$} & \multirow[b]{2}{*}{$\begin{array}{c}P \\
\text { Value }\end{array}$} \\
\hline & $\begin{array}{l}\text { No. of } \\
\text { Deaths }\end{array}$ & $\begin{array}{c}\text { Death Rate Per } \\
\text { I0 } 000 \text { Person-Years }\end{array}$ & $\begin{array}{l}\text { No. of } \\
\text { Deaths }\end{array}$ & $\begin{array}{l}\text { Death Rate Per } \\
\text { I0 } 000 \text { Person-Years }\end{array}$ & & \\
\hline \multicolumn{7}{|l|}{ All causes } \\
\hline Total & 10869 & 12.8 & 14716 & 14.6 & $0.98(0.96-1.01)^{d}$ & .11 \\
\hline Male & 10359 & 13.2 & 13680 & 15.6 & $0.97(0.95-0.99)$ & .02 \\
\hline Female & 510 & 8.6 & 1036 & 7.7 & $1.15(1.03-1.28)$ & .01 \\
\hline \multicolumn{7}{|l|}{ Disease-related causes (00I-799) } \\
\hline Total & 4916 & 5.8 & 8052 & 8.0 & $0.94(0.9 \mathrm{I}-0.98)^{d}$ & .002 \\
\hline Male & 4615 & 5.9 & 7398 & 8.4 & $0.93(0.90-0.97)$ & .001 \\
\hline Female & 301 & 5.1 & 654 & 4.9 & $1.10(0.96-1.27)$ & .16 \\
\hline \multicolumn{7}{|l|}{$\begin{array}{l}\text { Infectious and parasitic disease } \\
(001-139)\end{array}$} \\
\hline Total & 175 & 0.2 & 369 & 0.4 & $0.58(0.49-0.70)^{d}$ & $<.001$ \\
\hline Male & 165 & 0.2 & 350 & 0.4 & $0.56(0.47-0.68)$ & $<.001$ \\
\hline Female & 10 & 0.2 & 19 & 0.1 & I.I $3(0.52-2.43)$ & .75 \\
\hline \multicolumn{7}{|l|}{ All cancers (I40-208) } \\
\hline Total & 1807 & 2.1 & 3156 & 3.1 & $0.95(0.90-1.01)^{d}$ & .11 \\
\hline Male & 1652 & 2.1 & 2803 & 3.2 & $0.94(0.89-1.00)$ & .07 \\
\hline Female & 155 & 2.6 & 353 & 2.6 & $1.07(0.89-1.30)$ & .45 \\
\hline \multicolumn{7}{|l|}{ Circulatory system (390-459) } \\
\hline Total & $|76|$ & 2.1 & 2734 & 2.7 & $0.99(0.93-1.05)^{d}$ & .74 \\
\hline Male & $170 \mid$ & 2.2 & 2595 & 3.0 & $0.99(0.93-1.05)$ & .73 \\
\hline Female & 60 & 1.0 & 139 & 1.0 & $1.03(0.76-1.40)$ & .84 \\
\hline \multicolumn{7}{|l|}{ Respiratory system (460-519) } \\
\hline Total & 192 & 0.2 & 318 & 0.3 & $0.96(0.80-1.15)^{d}$ & .72 \\
\hline Male & 180 & 0.2 & 291 & 0.3 & $0.95(0.78-1.15)$ & .64 \\
\hline Female & 12 & 0.2 & 27 & 0.2 & $\mathrm{I} .07(0.54-2.1 \mathrm{I})$ & .85 \\
\hline \multicolumn{7}{|l|}{ Digestive system (520-579) } \\
\hline Total & 280 & 0.3 & 396 & 0.4 & $1.06(0.9 \mid-1.24)^{d}$ & .42 \\
\hline Male & 262 & 0.3 & 374 & 0.4 & $1.03(0.87-1.21)$ & .72 \\
\hline Female & 18 & 0.3 & 22 & 0.2 & $2.05(1.09-3.84)$ & .02 \\
\hline \multicolumn{7}{|l|}{ All external causes (E800-E999) } \\
\hline Total & 5183 & 6.1 & 5573 & 5.5 & $1.03(0.99-1.07)^{d}$ & .19 \\
\hline Male & 5010 & 6.4 & 5277 & 6.0 & $1.02(0.98-1.06)$ & .52 \\
\hline Female & 173 & 2.9 & 296 & 2.2 & $1.32(1.09-1.60)$ & .004 \\
\hline \multicolumn{7}{|l|}{ All accidents (E800-E929) } \\
\hline Total & 2864 & 3.4 & 3001 & 3.0 & $1.06(1.01-1.12)^{d}$ & .02 \\
\hline Male & 2774 & 3.5 & 2834 & 3.2 & $1.06(1.00-1.11)$ & .05 \\
\hline Female & 90 & 1.5 & 167 & 1.2 & $1.23(0.95-1.59)$ & .11 \\
\hline \multicolumn{7}{|c|}{ Motor vehicle accidents (E8I0-E825) } \\
\hline Total & 1776 & 2.1 & 1817 & 1.8 & $1.07(1.00-1.14)^{d}$ & .047 \\
\hline Male & 1710 & 2.2 & 1714 & 2.0 & $1.06(0.99-1.14)$ & .12 \\
\hline Female & 66 & 1.1 & 103 & 0.8 & $1.44(1.06-1.97)$ & .02 \\
\hline \multicolumn{7}{|l|}{ Suicide (E950-E959) } \\
\hline Total & $15 \mid 4$ & 1.8 & 1722 & 1.7 & $0.98(0.91-1.05)^{d}$ & .49 \\
\hline Male & 1468 & 1.9 & 1644 & 1.9 & $0.96(0.90-1.04)$ & .25 \\
\hline Female & 46 & 0.8 & 78 & 0.6 & $1.35(0.94-1.95)$ & .10 \\
\hline \multicolumn{7}{|l|}{ Homicide (E960-E969) } \\
\hline Total & 684 & 0.8 & 729 & 0.7 & $\mathrm{I} .00(0.90-\mathrm{I} . \mathrm{II})^{\mathrm{d}}$ & .95 \\
\hline Male & 652 & 0.8 & 683 & 0.8 & $0.97(0.87-1.09)$ & .58 \\
\hline Female & 32 & 0.5 & 46 & 0.3 & $1.52(0.97-2.40)$ & .07 \\
\hline
\end{tabular}

Abbreviations: $\mathrm{Cl}$, confidence interval; ICD-9, International Classification of Diseases, Ninth Revision.

${ }^{a}$ Data source: Unpublished data from the US Department of Defense's Defense Manpower Data Center.

${ }^{b}$ Adjusted rate ratio derived from a Cox proportional hazard model after controlling for race, branch of service, type of unit, and age.

${ }^{\mathrm{C}} P$ values derived from the Wald $\chi^{2}$ test of significance.

${ }^{\mathrm{d}}$ Also adjusted for sex. 


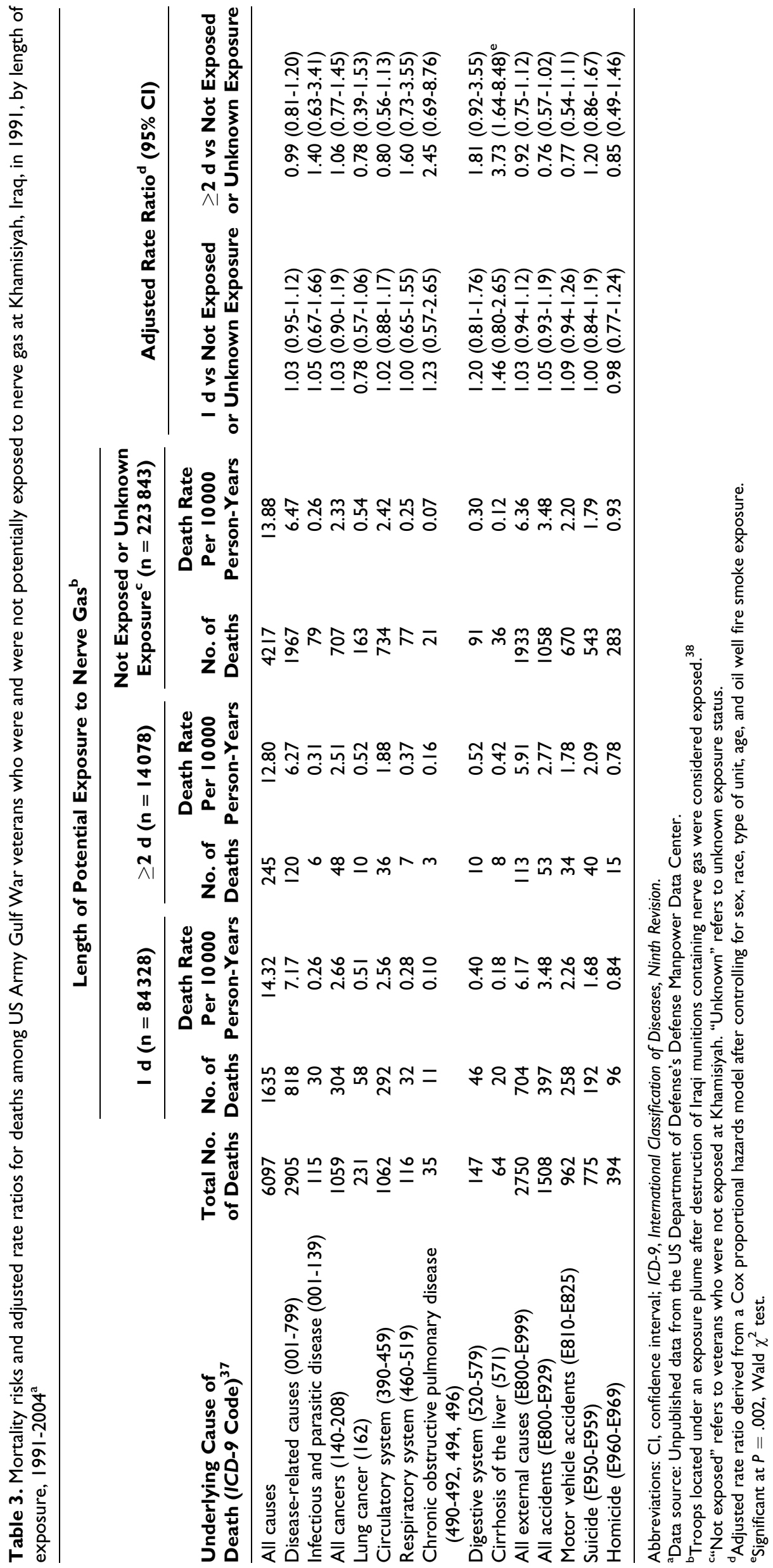


Table 4. Standard mortality ratios of US Gulf War veterans deployed between August I, 1990, and March I, I99I, and nondeployed veterans who served in the military during the same period compared with the US population, by cause of death, 199I-2004

\begin{tabular}{|c|c|c|c|c|c|c|}
\hline \multirow[b]{2}{*}{$\begin{array}{l}\text { Underlying Cause of Death } \\
\text { (ICD-9 Code })^{37}\end{array}$} & \multicolumn{2}{|r|}{ Total } & \multicolumn{2}{|r|}{ Men } & \multicolumn{2}{|r|}{ Women } \\
\hline & No. & $\begin{array}{l}\text { Standard Mortality } \\
\text { Ratio }(95 \% \mathrm{CI})\end{array}$ & No. & $\begin{array}{l}\text { Standard Mortality } \\
\text { Ratio }(95 \% \mathrm{Cl})\end{array}$ & No. & $\begin{array}{l}\text { Standard Mortality } \\
\text { Ratio }(95 \% \mathrm{CI})\end{array}$ \\
\hline \multicolumn{7}{|c|}{ Gulf War Veterans } \\
\hline Total no. of respondents & 621901 & & 578177 & & 43724 & \\
\hline All causes ${ }^{\mathrm{b}}$ & 10867 & $0.49(0.48-0.50)$ & 10357 & $0.48(0.47-0.49)$ & 510 & $0.61(0.55-0.66)$ \\
\hline Disease-related causes (00I-799) & 4622 & $0.35(0.34-0.36)$ & 4343 & $0.34(0.33-0.35)$ & 279 & $0.45(0.40-0.5 \mathrm{I})$ \\
\hline Infectious and parasitic disease (00I-139) & 60 & $0.03(0.02-0.03)$ & 58 & $0.02(0.02-0.03)$ & 2 & $0.03(0.00-0.11)$ \\
\hline All cancers $(140-208)$ & 1808 & $0.59(0.57-0.62)$ & 1653 & $0.58(0.56-0.61)$ & 155 & $0.73(0.62-0.86)$ \\
\hline Circulatory system (390-459) & 1759 & $0.43(0.41-0.45)$ & 1700 & $0.43(0.4 I-0.45)$ & 59 & $0.38(0.29-0.49)$ \\
\hline Respiratory system (460-519) & 192 & $0.30(0.26-0.34)$ & 180 & $0.30(0.25-0.34)$ & 12 & $0.33(0.17-0.57)$ \\
\hline Digestive system (520-579) & 280 & $0.29(0.26-0.33)$ & 262 & $0.28(0.25-0.32)$ & 18 & $0.49(0.29-0.78)$ \\
\hline All external causes (E800-E999) & 5182 & $0.63(0.6 I-0.64)$ & 5009 & $0.62(0.60-0.64)$ & 173 & $0.96(0.82-1.12)$ \\
\hline All accidents (E800-E929) & 2967 & $0.68(0.65-0.70)$ & 2872 & $0.67(0.65-0.70)$ & 95 & $0.89(0.72-1.09)$ \\
\hline Motor vehicle accidents (E8I0-E825) & 1776 & $0.81(0.77-0.85)$ & 1710 & $0.80(0.76-0.84)$ & 66 & $1.14(0.88-1.45)$ \\
\hline Suicide (E950-E959) & 1514 & $0.85(0.81-0.90)$ & 1468 & $0.84(0.80-0.88)$ & 46 & $1.60(1.17-2.13)$ \\
\hline Assault and homicide (E960-E978) & 701 & $0.34(0.32-0.37)$ & 669 & $0.33(0.3 \mathrm{I}-0.36)$ & 32 & $0.74(0.50-1.04)$ \\
\hline \multicolumn{7}{|c|}{ Non-Gulf War Veterans } \\
\hline Total no. of respondents & 746247 & & 647189 & & 99058 & \\
\hline All causes ${ }^{b}$ & 14406 & $0.49(0.48-0.49)$ & 13386 & $0.48(0.48-0.49)$ & 1020 & $0.52(0.49-0.56)$ \\
\hline Disease-related causes (00I-799) & 7445 & $0.38(0.37-0.39)$ & 6825 & $0.38(0.37-0.39)$ & 620 & $0.43(0.40-0.46)$ \\
\hline Infectious and parasitic disease (001-139) & 213 & $0.08(0.07-0.09)$ & 206 & $0.08(0.07-0.09)$ & 7 & $0.05(0.02-0.11)$ \\
\hline All cancers $(140-208)$ & 3078 & $0.60(0.58-0.63)$ & 2728 & $0.60(0.57-0.62)$ & 350 & $0.68(0.6 \mathrm{I}-0.75)$ \\
\hline Circulatory system (390-459) & 2676 & $0.42(0.40-0.44)$ & 2539 & $0.42(0.4 I-0.44)$ & 137 & $0.37(0.31-0.44)$ \\
\hline Respiratory system (460-519) & 314 & $0.32(0.28-0.35)$ & 288 & $0.32(0.28-0.36)$ & 26 & $0.30(0.20-0.44)$ \\
\hline Digestive system (520-579) & 384 & $0.27(0.25-0.30)$ & 364 & $0.28(0.25-0.31)$ & 20 & $0.23(0.14-0.36)$ \\
\hline All external causes (E800-E999) & 5453 & $0.60(0.59-0.62)$ & 5164 & $0.60(0.58-0.61)$ & 289 & $0.72(0.64-0.8 \mathrm{I})$ \\
\hline All accidents (E800-E929) & 3039 & $0.61(0.59-0.64)$ & 2872 & $0.61(0.59-0.63)$ & 167 & $0.69(0.59-0.8 \mathrm{I})$ \\
\hline Motor vehicle accidents (E8I0-E825) & 1779 & $0.74(0.70-0.77)$ & 1679 & $0.74(0.70-0.77)$ & 100 & $0.77(0.63-0.93)$ \\
\hline Suicide (E950-E959) & 1686 & $0.84(0.80-0.88)$ & 1610 & $0.83(0.79-0.87)$ & 76 & $1.14(0.90-1.43)$ \\
\hline Assault and homicide (E960-E978) & 728 & $0.35(0.33-0.38)$ & 682 & $0.34(0.32-0.37)$ & 46 & $0.50(0.37-0.67)$ \\
\hline
\end{tabular}

Abbreviations: $\mathrm{Cl}$, confidence interval; ICD-9, International Classification of Diseases, Ninth Revision.

aUnpublished data on Gulf War veterans come from the US Department of Defense's Defense Manpower Data Center. Data on the US population come from the Centers for Disease Control and Prevention. ${ }^{40}$

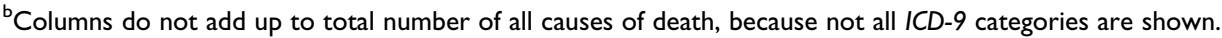

of suicide $(\mathrm{SMR}=1.60 ; 95 \% \mathrm{CI}, 1.17-2.13)$ than females in the US population overall. Female non-Gulf War veterans also had a greater, although not significant, risk of suicide than females in the US population (SMR $=1.14 ; 95 \% \mathrm{CI}$, 0.90-1.43; Table 4).

\section{Discussion}

The temporal trends in this cohort have been generally stable since the 7-year follow-up. ${ }^{14}$ All Gulf War veterans continued to have a higher mortality risk for external causes and accidents than non-Gulf War veterans. Male Gulf War veterans continued to have a higher risk of mortality from all accidents as compared with male non-Gulf War veterans, although the risk decreased with increasing length of follow-up. The higher risk of mortality from motor vehicle accidents among male Gulf War veterans was no longer significant, but the risk of mortality from motor vehicle accidents among female Gulf War veterans compared with female non-Gulf War veterans was still significant. Postdeployment mortality of Gulf War veterans in the United States was also consistent with postdeployment mortality of Gulf War veterans in the United Kingdom for the first 13 years after the war. ${ }^{42}$

Study results for female Gulf War veterans differed from those of their male Gulf War counterparts. Female Gulf War veterans had a higher risk of death from all causes when compared with female non-Gulf War veterans. This greater risk of all-cause mortality among female Gulf War veterans was mainly a result of their higher risk of mortality from external causes, of which motor vehicle accidents, suicide, and homicide constituted $83 \%$ of the total. 
Female Gulf War veterans had a $32 \%$ higher risk of mortality from external causes than female non-Gulf War veterans. Although the risk decreased since the 7-year follow-up period, female Gulf War veterans continued to have a significantly higher risk of motor vehicle accident mortality than female non-Gulf War veterans at the 2004 follow-up period. Compared with females in the US population, female Gulf War veterans had a higher risk of death by suicide.

Using mortality rate as an indicator for overall health, both groups of veterans in this cohort were healthier than the US population. This finding is consistent with other studies that found a healthy soldier effect. ${ }^{16,43-46}$ Younger veterans are generally healthier than their age-matched civilian counterparts because of requirements for initial health screenings upon entry into the military, physical fitness during active duty, and access to medical care.

Because of increased interest in the health effects of exposures among veterans, we analyzed some additional causes of death among exposed army veterans. Veterans who were potentially exposed to nerve agents at Khamisiyah for $\geq 2$ days had a significantly higher risk of death from cirrhosis of the liver. Other research on veterans exposed at Khamisiyah did not explain this finding. The most common causes of cirrhosis are infection with hepatitis B or hepatitis $\mathrm{C}$ and alcohol abuse; less common causes are bile duct disorders, hereditary diseases, medications, nonalcoholic fatty liver disease, and nonalcoholic steatohepatitis. ${ }^{47}$ Of the few studies that compared the overall health and diseases of Khamisiyah-exposed and nonexposed Gulf War veterans, none found any difference between the 2 groups. ${ }^{29,31}$ What was missing from the research on Gulf War veterans exposed at Khamisiyah were a description and comparison of health behaviors, such as alcohol abuse and drug use, which are common causes of cirrhosis. Further research into an explanation for this finding is warranted.

Chronic obstructive pulmonary disease is a leading cause of morbidity in the US population. ${ }^{48}$ Although smoking is a major risk factor for chronic obstructive pulmonary disease, research shows a relationship between chronic obstructive pulmonary disease and exposure to noxious particles. ${ }^{49} \mathrm{We}$ hypothesized that Gulf War veterans who were exposed to environmental stressors would have a higher risk of death from chronic obstructive pulmonary disease than those without exposures; however, our results did not support this hypothesis. A limitation is that we were unable to control for smoking status in our analyses.

\section{Strengths and Limitations}

This study had several strengths. The sample of approximately 1.3 million veterans included all veterans deployed to the Gulf War, as well as about half of those who were in the military at the time of the Gulf War but were not deployed, which resulted in reduced sampling error. ${ }^{50}$ Additionally, the large sample size allowed for substantial statistical power to detect small increased risks of mortality. ${ }^{17}$
This study also had several limitations. One is the possibility that nondeployed Gulf War veterans may have been less healthy than deployed Gulf War veterans at the time of deployment. However, this possibility was addressed in a previous follow-up study, which indicated that a potential selection bias would be transient and limited. ${ }^{14}$ Data on race, a variable used as a covariate in the model, were also limited in this historical Gulf War cohort. More extensive data on race/ethnicity might have altered the aRRs for some mortality outcomes. Finally, data on other health-related risk factors (eg, smoking) that may have contributed to certain causes of death were not available for this study cohort; therefore, we did not control for them in analyses.

\section{Conclusion}

In general, mortality patterns remained unchanged among all Gulf War veterans compared with non-Gulf War veterans. However, male Gulf War veterans no longer had a greater risk of motor vehicle accident mortality than male non-Gulf War veterans at the 13-year follow-up. Additionally, the mortality rate ratio for motor vehicle accident deaths among female Gulf War veterans compared with female non-Gulf War veterans also decreased at the 13-year follow-up as compared with the 7-year follow-up, although the ratio was still significant. Female Gulf War veterans had a significantly higher overall mortality risk than female non-Gulf War veterans, and this increased risk was mainly from external causes. Compared with the US population, female Gulf War veterans had a significantly higher risk of suicide.

We recommend that the vital status and mortality causes of cohorts of Gulf War and non-Gulf War veterans be periodically updated over time, including comparisons between these 2 groups and with the US population, to help understand any long-term effects of deployment and military service in general.

\section{Declaration of Conflicting Interests}

The author(s) declared no potential conflicts of interest with respect to the research, authorship, and/or publication of this article.

\section{Funding}

The author(s) disclosed receipt of the following financial support for the research, authorship, and/or publication of this article: This research was based on work supported by merit review funding (GWRA-019-04 S) awarded by the US Department of Veterans Affairs, Office of Research and Development.

\section{References}

1. Presidential Advisory Committee on Gulf War Veterans' Illnesses. Presidential Advisory Committee on GW Veterans' Illnesses: Final Report. Washington, DC: US Government Printing Office; 1996.

2. National Institutes of Health Technology Assessment Workshop Panel. The Persian Gulf experience and health. JAMA. 1994;272(5):391-396. 
3. Institute of Medicine. Health Consequences of Service During the Persian Gulf War: Recommendations for Research and Information Systems. Washington, DC: National Academy Press; 1996.

4. Iowa Persian Gulf Study Group. Self-reported illness and health status among Gulf War veterans: a population-based study. JAMA. 1997;277(3):238-245.

5. Kang HK, Mahan CM, Lee KY, Magee CA, Murphy FM. Illnesses among United States veterans of the Gulf War: a population-based survey of 30,000 veterans. J Occup Environ Med. 2000;42(5):491-501.

6. Li B, Mahan CM, Kang HK, Eisen SA, Engel CC. Longitudinal health study of US 1991 Gulf War veterans: changes in health status at 10-year follow-up. Am J Epidemiol. 2011;174(7): 761-768.

7. Kelsall HL, McKenzie DP, Sim MR, Leder K, Forbes AB, Dwyer T. Physical, psychological, and functional comorbidities of multisymptom illness in Australian male veterans of the 1991 Gulf War. Am J Epidemiol. 2009;170(8):1048-1056.

8. Unwin C, Blatchley N, Coker W, et al. Health of UK servicemen who served in Persian Gulf War. Lancet. 1999;353(9148): 169-178.

9. Kang HK, Natelson BH, Mahan CM, Lee KY, Murphy FM. Post-traumatic stress disorder and chronic fatigue syndromelike illness among Gulf War veterans: a population-based survey of 30,000 veterans. Am J Epidemiol. 2003;157(2): 141-148.

10. Toomey R, Kang HK, Karlinsky J, et al. Mental health of US Gulf War veterans 10 years after the war. Br J Psychiatry. 2007;190:358-393.

11. Fukuda K, Nisenbaum R, Stewart G, et al. Chronic multisymptom illness affecting air force veterans of the Gulf War. JAMA. 1998;280(11):981-988.

12. Blanchard MS, Eisen SA, Alpern R, et al. Chronic multisymptom illness complex in Gulf War I veterans 10 years later. Am J Epidemiol. 2006;163(1):66-75.

13. Kang HK, Li B, Mahan CM, Eisen SA, Engel CC. Health of US veterans of the 1991 Gulf War: a follow-up survey in 10 years. J Occup Environ Med. 2009;51(4):401-410.

14. Kang HK, Bullman TA. Mortality among US veterans of the Persian Gulf War: 7-year follow-up. Am J Epidemiol. 2001; 154(5):399-405.

15. Kang HK, Bullman TA, Macfarlane GJ, Gray GC. Mortality among US and UK veterans of the Persian Gulf War: a review. Occup Environ Med. 2002;59(12):794-799.

16. Kang HK, Bullman TA. Mortality among US veterans of the Persian Gulf War. N Engl J Med. 1996;335(20):1498-1504.

17. Writer JV, DeFraites RF, Brundage JF. Comparative mortality among US military personnel in the Persian Gulf region and worldwide during Operations Desert Shield and Desert Storm. JAMA. 1996;275(2):118-121.

18. Bullman TA, Mahan CM, Kang HK, Page WF. Mortality in US Army Gulf War veterans exposed to 1991 Khamisiyah chemical munitions destruction. Am J Public Health. 2005;95(8): 1382-1388.
19. Barth SK, Kang HK, Bullman TA, Wallin MT. Neurological mortality among US veterans of the Persian Gulf War: 13-year follow-up. Am J Ind Med. 2009;52(9):663-670.

20. Proctor SP, Heaton KJ, Heeren T, White RF. Effects of sarin and cyclosarin exposure during the 1991 Gulf War on neurobehavioral functioning in US army veterans. Neurotoxicology. 2006;27(6):931-939.

21. Heaton KJ, Palumbo CL, Proctor SP, Killiany RJ, YurgelunTodd DA, White RF. Quantitative magnetic resonance brain imaging in US army veterans of the 1991 Gulf War potentially exposed to sarin and cyclosarin. Neurotoxicology. 2007;28(4): 761-769.

22. Kalra R, Singh SP, Razani-Boroujerdi S, et al. Subclinical doses of the nerve gas sarin impair $\mathrm{T}$ cell responses through the autonomic nervous system. Toxicol Appl Pharmacol. 2002; 184(2):82-87.

23. Henderson RF, Barr EB, Blackwell WB, et al. Response of F344 rats to inhalation of subclinical levels of sarin: exploring potential causes of Gulf War Illness. Toxicol Ind Health. 2001; 17(5-10):294-297.

24. Chao LL, Rothlind JC, Cardenas VA, Meyerhoff DJ, Weiner MW. Effects of low-level exposure to sarin and cyclosarin during the 1991 Gulf War on brain function and brain structure in US veterans. Neurotoxicology. 2010;31(5):493-501.

25. Chao LL, Abadjian L, Hlavin J, Meyerhoff DJ, Weiner MW. Effects of low-level sarin and cyclosarin exposure and Gulf War Illness on brain structure and function: a study at $4 \mathrm{~T}$. Neurotoxicology. 2011;32(6):814-822.

26. Chao LL, Kriger S, Buckley S, Ng P, Mueller SG. Effects of low-level sarin and cyclosarin exposure on hippocampal subfields in Gulf War veterans. Neurotoxicology. 2014;44: 263-269.

27. Toomey R, Alpern R, Vasterling JJ, et al. Neuropsychological functioning of US Gulf War veterans 10 years after the war. J Int Neuropsychol Soc. 2009;15(5):717-729.

28. Davis LE, Eisen SA, Murphy FM, et al. Clinical and laboratory assessment of distal peripheral nerves in Gulf War veterans and spouses. Neurology. 2004;63(6):1070-1077.

29. Mahan CM, Page WF, Bullman TA, Kang HK. Health effects in army Gulf War veterans possibly exposed to chemical munitions destruction at Khamisiyah, Iraq: part I. Morbidity associated with potential exposure. Mil Med. 2005;170(11): 935-944.

30. Gackstetter GD, Hooper TI, DeBakey SF, et al. Fatal motor vehicle crashes among veterans of the 1991 Gulf War and exposure to munitions demolitions at Khamisiyah: a nested case-control study. Am J Ind Med. 2006;49(4):261-270.

31. McCauley LA, Lasarev M, Sticker D, Rischitelli DG, Spencer PS. Illness experience of Gulf War veterans possibly exposed to chemical warfare agents. Am J Prev Med. 2002;23(3): 200-206.

32. Kelsall HL, Sim MR, Forbes AB, et al. Respiratory health status of Australian veterans of the 1991 Gulf War and the effects of exposure to oil fire smoke and dust storms. Thorax. 2004;59(10):897-903. 
33. Lange JL, Schwartz DA, Doebbeling BN, Heller JM, Thorne PS. Exposures to the Kuwait oil fires and their association with asthma and bronchitis among Gulf War veterans. Environ Health Perspect. 2002;110(11):1141-1146.

34. Cowan DN, Lange JL, Heller J, Kirkpatrick J, DeBakey S. A case-control study of asthma among US Army Gulf War veterans and modeled exposure to oil well fire smoke. Mil Med. 2002;167(9):777-782.

35. Karlinsky JB, Blanchard M, Alpern R, et al. Late prevalence of respiratory symptoms and pulmonary function abnormalities in Gulf War I veterans. Arch Intern Med. 2004;164(22): 2488-2491.

36. Smith TC, Heller JM, Hooper TI, Gackstetter GD, Gray GC. Are Gulf War veterans experiencing illness due to exposure to smoke from Kuwaiti oil well fires? Examination of Department of Defense hospitalization data. Am J Epidemiol. 2002;155(10): 908-917.

37. World Health Organization. International Classification of Diseases: Manual of the International Classification of Diseases, Injuries, and Causes of Death. Ninth Revision. Vol 1. Geneva, Switzerland: World Health Organization; 1977.

38. Winkenwerder W. Case narrative: US demolition operations at Khamisiyah. Final report. http://www.gulflink.osd.mil/kha misiyah_iii. Published April 2002. Accessed August 2, 2016.

39. Rostker B. Environmental Exposure Report: Oil Well Fires. Washington, DC: Office of the Special Assistant to the Deputy Secretary of Defense for Gulf War Illnesses; 2000.

40. Centers for Disease Control and Prevention, National Institute for Occupational Safety and Health. NIOSH life table analysis system version 3.0.1. http://www.cdc.gov/niosh/ltas. Published December 2010. Accessed August 2, 2016.

41. SAS Institute, Inc. SAS/STAT Version 9.4. Cary, NC: SAS Institute, Inc; 2013.

42. Macfarlane GJ, Hotopf M, Maconochie N, Blatchley N, Richards A, Lunt M. Long-term mortality amongst Gulf War veterans: is there a relationship with experiences during deployment and subsequent morbidity? Int J Epidemiol. 2005;34(6):1403-1408.

43. Seltzer CC, Jablon S. Effects of selection on mortality. Am J Epidemiol. 1974;100(5):367-372.

44. Rothberg JM, Bartone PT, Holloway HC, Marlowe DH. Life and death in the US Army: in corpore sano. JAMA. 1990; 264(17):2241-2244.

45. Thomas TL, Kang HK, Dalager NA. Mortality among women Vietnam veterans, 1973-1987. Am J Epidemiol. 1991;34(9): 973-980.

46. Watanabe KK, Kang HK. Military service in Vietnam and the risk of death from trauma and selected cancers. Am J Epidemiol. 1995;5(5):407-412.

47. MedlinePlus. Cirrhosis. http://www.nlm.nih.gov/medlineplus/ ency/article/000255.htm. Accessed January 28, 2015.

48. Akinbami LJ, Liu X. Chronic obstructive pulmonary disease among adults aged 18 and over in the United States, 1998-2009. NCHS Data Brief. 2011;(63):1-8.

49. Liu S, Zhou Y, Wang X, et al. Biomass fuels are the probable risk factor for chronic obstructive pulmonary disease in rural South China. Thorax. 2007;62(10):889-897.

50. Kang HK, Bullman TA. Counterpoint: negligible "healthywarrior effect" on Gulf War veterans' mortality. Am J Epidemiol. 1998;148(4):324-345. 